- The oral cancer awareness campaign was received positively by GDPs.

- The campaign's television advertisement had been seen by $78 \%$ of the respondents. The vast majority agreed that it was helpful

- The campaign appears to have had some impact on practices in the West of Scotland.

- Many dentists reported non-registered patients had attended asking for advice regarding a worrying lesion.

- It will be important to assess the impact of the campaign on patients' awareness of oral cancer over a longer time period

\title{
General dental practitioners' perceptions of the West of Scotland Cancer Awareness Programme oral cancer campaign
}

\author{
J. Rodgers ${ }^{1}$ and L. M. D. Macpherson ${ }^{2}$
}

\begin{abstract}
Objectives The 2003/04 West of Scotland Cancer Awareness Programme (WoSCAP) oral cancer campaign was designed to raise public awareness of the signs and symptoms of oral cancer. The objectives of this study were to explore general dental practitioners' (GDPs) awareness and perceptions of the campaign, and its impact on local dental practices. Methods A self-completing questionnaire was sent to GDPs in the West of Scotland $(N=983)$ at the conclusion of the public awareness campaign. Results A response rate of 68.6\% was achieved. Most dentists (92\%) had heard of the campaign and a large percentage had displayed the promotional materials in their practice. The majority of respondents rated the campaign materials, including a television advertisement, in a very positive manner. Over $40 \%$ of dentists reported that, during the active phase of the campaign, patients had asked for information concerning the programme, and $66 \%$ indicated that registered patients had asked for advice regarding a specific lesion. Additionally, 41\% of dentists reported non-registered patients had attended asking for advice regarding a 'worrying' lesion. Over $60 \%$ of dentists had referred a patient during the campaign and $40 \%$ of these practitioners indicated an increased referral rate during this period.

Conclusions Most respondents were positive in their assessment of the campaign and reported an increased awareness of oral cancer among patients.
\end{abstract}

\section{INTRODUCTION}

In the United Kingdom, there are approximately 3,500 new cases and 1,800 deaths from oral cancer each year. In Scotland, over 500 oral cancer cases are diagnosed per annum and despite recent advances in the management of the disease, poor survival rates persist. Overall, the relative five-year survival rate for males in Scotland is only $44 \%$, while for females it is $49 \%$.

\footnotetext{
Specialist Registrar in Dental Public Health, Lanarkshire and Argyll \& Clyde NHS Boards; $2^{*}$ Professor and Honorary Consultant in Dental Public Health, University of Glasgow Dental School, 378 Sauchiehall Street, Glasgow, G2 3JZ.

*Correspondence to: Dr Lorna Macpherson

Email:I.macpherson@dental.gla.ac.uk
}

\section{Refereed paper}

Accepted 28 June 2005

DOI: $10.1038 /$ sj.bdj.4813733

(๑) British Dental Journal 2006; 200: 693-697
As well as the biology of tumour and host response, the most important factor in determining prognosis of the disease is the stage of the tumour at presentation, taking into account the size, site and local spread of the tumour. Smaller, earlier lesions have a better prognosis. ${ }^{2}$ Unfortunately, a high proportion of oral cancer patients from the West of Scotland first present to the health profession with tumours at a late stage. This makes the management of the disease more complex and the morbidity associated with the treatment is significantly increased. ${ }^{3}$

In 2002, five NHS Boards in the West of Scotland obtained funding from the New Opportunities Fund (NOF), to carry out a cancer awareness campaign entitled the West of Scotland Cancer Awareness Programme (WoSCAP). After a period of consultation with professional groups and the general public, the two cancers chosen for the programme were oral cancer and colo-rectal cancer. Separate programmes were developed for each of these cancers, with initial activity directed towards the oral cancer campaign.

Initial background research found a very low awareness of oral cancer among the West of Scotland population, with only 6\% mentioning this site spontaneously when asked to recall cancer types. ${ }^{4}$ This low level of awareness is similar to the findings of previous work in the UK. ${ }^{5}$ The purpose of the campaign was to raise awareness of the signs and symptoms of oral cancer amongst a pre-determined target population living in the West of Scotland, and to encourage them to go to health services with any suspicion of oral cancer. The target population was males and females over the age of 45 years. The campaign's slogan was 'if in doubt, get it checked out'. The programme did not aim to increase knowledge of the risk factors of oral cancer.

Further objectives were to ensure that health professionals were aware of the campaign and of the key messages prior to the public launch and to engage their support to ensure that services could sustain potential additional demand created by the campaign. The programme team organised training for primary care health professionals in the West of Scotland and liaised with secondary care clinicians in an attempt to ensure that referral systems and secondary care facilities would be able to cope with any increase in workload that may result from the programme.

The campaign began in September 2003 with accredited CPD training events. Every general dental and medical practitioner and 
every community pharmacist was invited to one of the 25 training sessions held across the West of Scotland. Overall, 1,280 health professionals attended the training. General dental and medical practices were also sent promotional material such as posters, leaflets and information for their premises. The public campaign was launched in October 2003 with reports about oral cancer on the local news, a 40-second television commercial and radio coverage. The public campaign ran in two, five-week phases, the first from October until November 2003, and the second phase from February to March 2004. The television and radio advertisements were broadcast during both of these time periods.

The main aim of this study was to evaluate the West of Scotland Cancer Awareness Programme (WoSCAP) oral cancer campaign, from the perspective of dental practitioners' awareness and perceptions of the programme.

\section{METHODS}

Following piloting, a postal questionnaire was sent to all NHS general dental practitioners (excluding orthodontic practitioners) in the five NHS Boards taking part in the WoSCAP oral cancer campaign. The forms were sent out at the end of the second phase of the public campaign (April 2004). A follow-up mailing to non-respondents occurred after an interval of five weeks.

The questionnaire had 18 questions and was estimated to take under 10 minutes to complete. The main themes covered were respondent demographic information, level of awareness of the campaign, use of programme materials, attendance at training events, and the impact of the campaign in relation to patient awareness and referral practices.

Analyses of the data were carried out using the SPSS for Windows software package. Frequency tables were produced and cross-tabulations performed, where appropriate.

\section{RESULTS}

Of the 983 questionnaires distributed to practitioners, 674 completed forms were returned, representing a response rate of $68.6 \%$. The responses by NHS Board are shown in Table 1, and ranged from $58 \%$ to $85 \%$.

Overall, $66.2 \%$ of respondents were male and 33.8\% female. A large proportion of the practitioners were in the 30-44 and 45-59 year-old age bands (45.3\% and 35.9\%, respectively) with $15.6 \%$ being under 30 and 3.3\% being aged 60 years or over.

Postcode information was provided in sufficient detail to obtain deprivation category (DEPCAT) scores ${ }^{6}$ for practice locations in $74 \%$ of cases. The DEPCAT profile of these practices is shown in Table 2 and is compared to the profile of all dental practices in the West of Scotland Board areas.

Almost all the respondents (92.4\%) had heard of the campaign.

\begin{tabular}{|c|c|c|}
\hline NHS Board & $\begin{array}{l}\text { Number }(\%) \text { of } \\
\text { dental respondents }\end{array}$ & $\begin{array}{l}\text { Response rate }(\%) \\
\text { of each NHS Board }\end{array}$ \\
\hline Ayrshire and Arran & $100(14.8)$ & 100/131 (76.3) \\
\hline Argyll and Clyde & $121(18)$ & $121 / 175(69.1)$ \\
\hline Greater Glasgow & $285(42.4)$ & 285/421 (67.7) \\
\hline Lanarkshire & 125 (18.5) & $125 / 216(57.9)$ \\
\hline Forth Valley & $34(5)$ & $34 / 40$ (85) \\
\hline No response & $9(1.3)$ & - \\
\hline Total & $674(100)$ & $674 / 983(68.6)$ \\
\hline
\end{tabular}

\begin{tabular}{|c|c|c|}
\hline $\begin{array}{l}\text { DEPCAT } \\
1=\text { most affluent }, 7= \\
\text { most deprived }\end{array}$ & $\begin{array}{l}\text { No. of Respondents' } \\
\text { Practices }(\%)\end{array}$ & $\begin{array}{l}\text { No. of Practices in the } \\
\text { West of Scotland (\%) }\end{array}$ \\
\hline 1 & $26(5.2)$ & $33(6.9)$ \\
\hline 2 & $62(12.5)$ & $56(11.6)$ \\
\hline 3 & $67(13.5)$ & $63(13.1)$ \\
\hline 4 & $78(15.7)$ & 105 (21.8) \\
\hline 5 & $112(22.5)$ & $84(17.5)$ \\
\hline 6 & $82(16.5)$ & 88 (18.3) \\
\hline 7 & $70(14.1)$ & $52(10.8)$ \\
\hline Total & 497 & 481 \\
\hline
\end{tabular}

\begin{tabular}{|c|c|c|c|c|}
\hline Promotion & $\begin{array}{l}\text { Yes } \\
\text { No. }(\%)\end{array}$ & $\begin{array}{l}\text { No } \\
\text { No. }(\%)\end{array}$ & $\begin{array}{l}\text { Don't Know/ } \\
\text { No Response } \\
\text { No. }(\%)\end{array}$ & Total \\
\hline $\begin{array}{l}\text { Heard of } \\
\text { Campaign }\end{array}$ & 623 (92.4) & $44(6.5)$ & $7(1.0)$ & 674 \\
\hline Received posters & 477 (70.8) & $66(9.8)$ & $131(19.5)$ & 674 \\
\hline Received leaflets & 504 (74.8\%) & 48 (7.1\%) & $122(18.1 \%)$ & 674 \\
\hline $\begin{array}{l}\text { Displayed } \\
\text { posters }\end{array}$ & 370 (54.9) & 201 (29.8) & 103 (15.3) & 674 \\
\hline $\begin{array}{l}\text { Displayed } \\
\text { leaflets }\end{array}$ & 467 (69.3) & 111 (16.5) & $96(14.2)$ & 674 \\
\hline $\begin{array}{l}\text { Used leaflet as a } \\
\text { discussion aid }\end{array}$ & 135 (20.0) & $473(70.2)$ & 66 (9.8) & 674 \\
\hline
\end{tabular}

Most reported they had received the WoSCAP posters (70.8\%) and leaflets $(74.8 \%)$. The proportions displaying the material in their surgery were 54.9\% (posters) and 69.3\% (leaflets). However, a lower proportion (20\%) used the leaflet as a discussion aid with their patients (Table 3). Nevertheless, in total, 58.2\% responded that the posters were either 'very useful' or 'useful', with the corresponding figure for the leaflets being 66.3\%.

The oral cancer campaign's television advertisement had been seen by $526(78 \%)$ of the respondents. The vast majority $(98.4 \%)$ who had seen it 'strongly agreed' or 'agreed' that it was helpful concerning the delivery of advice on the signs and symptoms of the disease. Similarly, a very high proportion of respondents (95.5\%) either 'strongly agreed' or 'agreed' that the advice on where to seek help was useful (Table 4).

A much lower percentage of practitioners (23.9\%) had heard the radio broadcast. Of these individuals, again, almost all either 'strongly agreed' or 'agreed' that the signs and symptoms advice given was helpful and that the information on where to seek help was useful (Table 4).

The WoSCAP training course was attended by over one third (38.3\%) of the respondents, and the most common reason for nonattendance was that the dentist had recently attended another course on oral cancer (36\%). Other common reasons given for not attending were time pressures, depletion of post-graduate allowance and holidays.

The dentists were asked to report if they noticed an impact on their dental practice during and immediately after the first (Oct 03-Jan 04) and second phases (Feb-April 04) of the WoSCAP campaign. For both time periods, over $40 \%$ of practitioners reported patients had asked about the oral cancer campaign and a similar proportion of respondents indicated they had an increase in 


\begin{tabular}{|c|c|c|c|c|c|}
\hline Advice & $\begin{array}{l}\text { Strongly } \\
\text { agree } \\
\text { No. }(\%)\end{array}$ & $\begin{array}{l}\text { Agree } \\
\text { No. (\%) }\end{array}$ & $\begin{array}{l}\text { Disagree } \\
\text { No. }(\%)\end{array}$ & $\begin{array}{l}\text { Strongly } \\
\text { disagree } \\
\text { No. (\%) }\end{array}$ & $\begin{array}{l}\text { No } \\
\text { response } \\
\text { No. }(\%)\end{array}$ \\
\hline $\begin{array}{l}\text { Signs and } \\
\text { symptoms advice } \\
\text { on the TV advert } \\
\text { was useful }\end{array}$ & $\begin{array}{l}217 \\
(41.2)\end{array}$ & $\begin{array}{l}301 \\
(57.2)\end{array}$ & $5(1.0)$ & $1(0.2)$ & $2(0.4)$ \\
\hline $\begin{array}{l}\text { Advice on where } \\
\text { to seek help on } \\
\text { the TV advert was } \\
\text { useful }\end{array}$ & $\begin{array}{l}205 \\
(39.0)\end{array}$ & $\begin{array}{l}297 \\
(56.5)\end{array}$ & $14(2.7)$ & $7(1.3)$ & $3(0.6)$ \\
\hline $\begin{array}{l}\text { Signs and } \\
\text { symptoms advice } \\
\text { on the radio } \\
\text { advert was useful }\end{array}$ & $61(37.9)$ & $97(60.2)$ & 0 & $1(0.6)$ & $2(1.2)$ \\
\hline $\begin{array}{l}\text { Advice on where } \\
\text { to seek help on } \\
\text { the radio advert } \\
\text { was useful }\end{array}$ & $68(42.2)$ & $85(52.8)$ & $2(1.2)$ & $3(1.9)$ & $3(1.9)$ \\
\hline
\end{tabular}

non-registered patients asking for advice concerning a worrying lesion (Table 5). For the first phase of the campaign, a significant relationship ( $p=0.043$ ) was seen between DEPCAT of practice and reported increase in non-registered patients seeking advice, with more dentists reporting advice being sought in practices located in the more deprived areas. During phase 2 this was not significant $(p=0.064)$. Approximately two-thirds of the dentists stated there had been an increase in the number of registered patients asking for advice on this topic, however, no relationship to DEPCAT of practice was seen $(\mathrm{p}=0.815$ and $\mathrm{p}=0.354$ for phases 1 and 2 , respectively).

During the campaign periods, $12.3 \%$ of general dental practitioners had received referrals from community pharmacists and 28.9\% had received referrals from general medical practitioners concerning intra-oral soft tissue lesions. However, in most cases where referrals had been received, the absolute numbers had been low (Table 6).

Regarding the practitioners' own referral practices, over $60 \%$ had referred a patient with a 'worrying' lesion to a secondary care centre during the time of the campaign and over $90 \%$ of these dentists had referred between one and five patients. All of the dentists who had referred a patient during this period had been aware of the campaign. A sizeable proportion (40\%) of dentists who referred patients reported that this was more than their usual number. No relationship was seen between attendance at a WoSCAP training event and referral practice $(\mathrm{p}=0.311)$. Of the 405 dentists who had referred patients to a referral centre, 96\% thought the referral pathway was easy to use, $80 \%$ considered it efficient and $68 \%$ thought it time-saving.

The dentists were invited to make comments about the WoSCAP oral cancer campaign. Of the 674 respondents, 155 added a comment. Of these 18 were of a negative nature and the rest were positive. Most of the positive comments concerned the nature of the campaign and the positive impact on patients. Dentists stressed the value of the campaign in addressing the low awareness of this disease and they seemed glad that such a large campaign was focusing on an oral topic. Some of the comments were very enthusiastic eg 'very worthwhile, a lifesaver for many, I expect' and others talked of changed patient's views: 'for the first time patients are asking questions relating to oral cancer before I examine them' The dentists also talked of their own changed behaviour: 'I now

Table 5 Impact of the WoSCAP oral cancer campaign on the dental practices
with regard to patients asking for related information or advice
\begin{tabular}{l|l|l} 
Impact & $\begin{array}{l}\text { Phase 1 } \\
\text { No. of GDPs (\%) }\end{array}$ & $\begin{array}{l}\text { Phase } 2 \\
\text { No. of GDPs (\%) }\end{array}$ \\
\hline $\begin{array}{l}\text { Patients asking for information } \\
\text { relating to campaign }\end{array}$ & $304(45.1)$ & $278(41.2)$ \\
\hline $\begin{array}{l}\text { Increased numbers of non } \\
\text { registered patients asking for } \\
\text { advice }\end{array}$ & $280(41.5)$ & $274(40.7)$ \\
\hline $\begin{array}{l}\text { Increased numbers of registered } \\
\text { patients asking for advice }\end{array}$ & $454(67.4)$ & $448(66.5)$
\end{tabular}

$\begin{aligned} & \text { Table } 6 \text { Number of referrals received by respondents from community } \\
& \text { pharmacists and general medical practitioners during campaign }(N=674)\end{aligned}$
\begin{tabular}{l|l|l}
$\begin{array}{l}\text { Number of patient } \\
\text { referrals received by } \\
\text { GDPs }\end{array}$ & $\begin{array}{l}\text { Referrals from } \\
\text { community } \\
\text { pharmacists } \\
\text { No. GDPs }(\%)\end{array}$ & $\begin{array}{l}\text { Referrals from general } \\
\text { medical practitioners } \\
\text { No. GDPs }(\%)\end{array}$ \\
\hline 0 & $591(87.7)$ & $479(71.1)$ \\
\hline $1-5$ & $74(11)$ & $174(25.8)$ \\
\hline $6-10$ & $6(0.9)$ & $16(2.4)$ \\
\hline$>10$ & $3(0.4)$ & $5(0.7)$ \\
\hline Total & 674 & 674
\end{tabular}

do a regular thorough cancer check for every patient'. The dentists also commented on a general need for 'screening' patients for oral cancer but acknowledged that most of the at-risk population were not registered with a dental practitioner. Additionally, a number of dentists said that they now felt well supported in practice since meeting the consultants who they were referring patients to at the training events. Overall, the majority of the positive comments were concerned with increased awareness of both registered and non-registered patients within their practices.

The small numbers of negative comments were mainly focused on a few reported difficulties in using the referral pathways and on the problem of dentists not being remunerated for the perceived extra work associated with an oral cancer examination and increased number of referrals.

\section{DISCUSSION}

Diagnosing oral cancer at an early stage is crucial to reducing morbidity and relates in part to the survival outcome. ${ }^{7}$ Other factors such as inherent growth rate of the tumour and the immune response of the host must be taken into consideration. ${ }^{8}$ However, as the growth rate and the immune response of the host are impossible to alter, the best defence against oral cancer is early diagnosis and commencement of treatment. ${ }^{9}$ Multivariate analyses of the effectiveness of treatments for invasive oral cancer have consistently identified the stage of disease as an important factor, ie that treatment of 'early disease', 'small' or 'low stage' tumours is shown to improve survival compared to 'late detected', 'large' or 'higher stage' oral malignancies. ${ }^{10}$ However, few of these studies take account of the potential for lead-time bias, ie the possibility that people live with the diagnosis longer but do not necessarily survive longer (than they would have without the early diagnosis).

Despite the burdens that oral cancer places on individual patients and society, in developed countries, this cancer receives considerably less attention than many other diseases in terms of media exposure, educational programmes and funding for research. ${ }^{5}$ Belt reported in 2001 that 'oral cancer does not register high on the scale of health concerns in the minds of the general public' and argued that the public are not well informed about oral 
cancer because it has not been the principal interest or focus of any cancer awareness programme. ${ }^{11}$

Thus public awareness of oral cancer is low, possibly accounting for the time delay in people presenting to the health service for treatment.

There is widespread consensus that opportunistic screening for oral cancer should form part of the general oral examination by a dentist, and that this should improve the early detection rates of oral cancer among the registered population. ${ }^{12}$ However, as the percentage of people using dental services is low, and those in the high risk groups lower still, ${ }^{13}$ an increase in awareness is first required to draw attention to the disease among the general public, in order to encourage more people to attend for an oral examination. ${ }^{3}$ Thus, the principal aim of the WoSCAP oral cancer campaign was to raise awareness of the disease amongst the public, particularly those over 45 years, and to encourage anyone with a potential problem to have it 'checked out'.

Although a small number of oral cancer awareness raising campaigns have been reported in the literature over the last decade, including those in the UK, ${ }^{3}$ USA $^{14}$ and India, ${ }^{15,16}$ there have been relatively few such interventions focussing on this disease alone, and therefore the potential benefits of such campaigns are difficult to determine.

The general dental practitioner survey formed only one component of the evaluation of this WoSCAP oral cancer programme. Other studies are investigating changes in levels of public awareness of the disease before, during and after the campaign; the diagnosis of cases referred rapidly to secondary care clinics during the programme; and the impact on general medical services.

The dental questionnaire was sent to the population of general dental practitioners in the five participating NHS Boards. The overall response rate was $69 \%$. It could be argued that the $31 \%$ non-respondents constitutes a selection bias, in that those who responded were more likely to have had an interest in, and to have participated in the campaign.

A large proportion (45\%) of the participating dentists were aged 30-44 years old, reflecting the age distribution of the Scottish dental workforce rather that a greater tendency for this group to return questionnaires. Additionally, the majority of respondents were male, again reflecting the distribution of sexes in the Scottish dental workforce. ${ }^{17}$

The awareness of the dentists concerning the television broadcast, posters and leaflets was high, whilst a much lower proportion had heard the radio advertisement. This was to be expected as the television broadcast formed the major component of the mass media campaign and was aired much more frequently than the radio advertisement. The television broadcast used three actual oral cancer patients. The first two discussed how they had become aware of an abnormality in their mouth and sought professional advice quickly and as a result had received treatment at an early stage. The third patient had obviously received much more radical surgery and speech difficulties were apparent. He indicated that he had not done anything for a while after becoming aware of a mouth problem but now wished he had. The broadcast ended with a voice-over of the signs and symptoms of mouth cancer and advised anyone with concerns to visit their dentist, doctor or pharmacist. The vast majority of dentists who had seen the advertisement felt these two key messages had been delivered in an appropriate manner for the target group.

The television advert was shown on average three times per day for the duration of the public campaign, during day-time and prime-time television shows. The estimated reach of the television campaign by the advertising company was $80 \%$ of the target group would see the advert at least once. The radio advert was broadcast on all local radio stations in the West of Scotland and had a target of 30 spots for the duration of the public campaign. The estimated reach of the radio campaign by the advertising company was that $20 \%$ of the target group would hear the advert at least once.

Although $69.3 \%$ of the respondents reported that programme leaflets were displayed in their practice, only 20\% indicated they had used the leaflet as a discussion aid with their patients. While this had been one aim regarding use of the leaflet, the major objective was to provide written material for patients to read in their own time. The leaflets evaluated positively with the practitioners, with two thirds of respondents considering them to be a useful resource.

The overall attendance at the training events was good, and over one third of the GDP respondents had attended one of the 25 scheduled sessions. These were held in the evening, across the five NHS Board areas and gave continuing professional development points. The events occurred prior to the public campaign. The most common reason for not attending was recent attendance at another oral cancer course. Thus, a relatively high proportion of general dental practitioners had received training in oral cancer-related topics shortly before the commencement of the campaign.

As well as covering the epidemiology and clinical presentation of the disease, the training sessions gave local consultants in oral and maxillofacial surgery, oral medicine and plastic surgery the opportunity to describe referral pathways for their particular unit, and to discuss the types of cases and lesions which should be considered for referral.

The campaign appears to have had some impact on a large proportion of practices in the West of Scotland, with over 40\% of dentists stating that patients had asked for general information relating to the campaign, and over $66 \%$ of dentists reported registered patients had asked for advice regarding a specific lesion. Additionally, a large number (41\%) of dentists reported non-registered patients had attended asking for advice regarding a worrying lesion. The findings suggest that such a campaign may have the potential to affect to some extent the large group of non-registered patients in the West of Scotland. However, it will be important to assess the impact of the campaign on patients' awareness of oral cancer over a longer time period.

Over 60\% of GDPs had referred a patient to a secondary referral centre during the time of the campaign. The majority of these dentists had referred between one and five patients, and 40\% of them responded that this was more than their usual number of referrals. It is to be expected that there would be more referral activity during the time of an awareness campaign. Of the general dental practitioners who had used the referral pathway, the majority responded that they had found it easy to use, efficient and timesaving. In many areas the referral pathway had not changed, but the consultants at the training events had assured the practitioners that they would be willing to see patients at short notice. Whilst the dental practitioners increased the referral numbers to secondary care during the campaign and were generally satisfied with their local referral pathway, it will be important to ascertain whether appropriate use was made of such referral services. Research is underway to determine the diagnoses associated with referrals to these services before, during and immediately after the campaign periods.

\section{CONCLUSIONS}

Almost all general dental practitioner respondents in the West of Scotland were aware of the WoSCAP oral cancer campaign. The majority viewed the campaign in a positive manner and a large proportion of practitioners reported increased patient awareness concerning oral cancer. Although a relatively high number of the practitioners attended the programme's specific training events or another oral cancer course not long before the active phase of the campaign, further work is required to determine the appropriateness of the increased referral practice reported by the GDPs during this period. 
We thank the general dental practitioners who participated in this study, $\mathrm{Mr}$ George Taylor, Clinical Governance Adviser and Lead Dental Audit Facilitator, the IT Department of Lanarkshire NHS Board and the support of the West of Scotland Cancer Awareness Programme.

1. Macpherson L M D, Gibson J, Binnie V I, Conway D I. Oral cancer prevention and detection for the primary health care team. $2^{\text {nd }}$ ed. Glasgow: University of Glasgow, 2003.

2. Horowitz A M, Goodman H S, Yellowitz J A, Nourjah P A. The need for health promotion in oral cancer prevention and early detection. J Public Health Dent 1996; 56:319-330

3. Clark, A. Oral cancer prevention and early detection. Nursing Standard 1999; $13: 43$ 47.

4. West of Scotland Cancer Awareness Programme. www.woscap.co.uk (accessed $12^{\text {th }}$ November 2004).

5. Warnakulasuriya K A A S, Harris C K, Scarrott D M et al. An alarming lack of public awareness towards oral cancer. Br Dent J 1999; 187: 319-322.

6. McLoone P. Carstairs scores for Scottish postcode sectors from the 1991 census. Glasgow: University of Glasgow, 1994.

7. Johnson N W. Warnakulasuriya K A A S. Epidemiology and aetiology of oral cancer in the United Kingdom. Community Dent Health 1993; 10 (S1):13-29.
8. Chamberlain J. Evaluation of screening for cancer. Community Dent Health 1993; 10 (S1): 5-11.

9. Swinson $B D$, Witherow $H_{1}$ Amin $M$ et al. Principles of management in oral cancer. Hospital Med 2003; 64: No. 7

10. Rosati C. Prevention of oral cancer. In Canadian Task Force on the Periodic Health Examination. Canadian guide to preventative health care. pp 826-836. Ottawa: Health Canada, 1994

11. Belt D. National campaign will promote oral cancer awareness. Canadian Dent $J$ 2001; 29: 551-553.

12. Blinkhorn A S, Jones J H. Behavioural aspects of oral cancer screening. Community Dent Health 1993; 10 (S1): 63-69.

13. Scottish Office Department of Health. The oral health strategy for Scotland. Edinburgh: Scottish Office, 1995

14. Bonner P. National oral cancer awareness programme. Oral Head Neck Nursing 1998 ; 16: $15-19$.

15. Sharma D. Delhi launches cancer awareness campaign. Lancet Oncology 2002; 3 : 133.

16. Gupta P C, Mehta FS, Pindborg J J, Bhonsle R B, Daftery D K. Primary prevention trial of oral cancer in India: a 10-year follow up. J Oral Pathol Med 1992; 21: 433-439.

17. NHS Education for Scotland. Workforce planning for dentistry in Scotland. ISD Scotland, 2004. www.isdscotland.org (accessed $2^{\text {nd }}$ Aug 2004). 